\title{
Décimas presidenciales. Una lectura alternativa de El Señor Presidente de Miguel Ángel Asturias
}

\author{
Décimas of the President, an alternative reading of \\ Mister President, by Miguel Ángel Asturias
}

\author{
Daniel Solano Ulate \\ Escuela de Danza \\ Universidad Nacional, Costa Rica \\ daniel.solano.ulate@una.cr \\ Un agradecimiento a los maestros \\ Alexis Díaz-Pimienta y Jorge Drexler \\ por acercarme al mundo de las décimas \\ y la improvisación poética latinoamericana
}

\begin{abstract}
Resumen
En este trabajo abordo el contexto alrededor de la novela El Señor Presidente del guatemalteco Miguel Ángel Asturias, publicada en 1946. Contemplo un repaso breve por la historia de Guatemala y su Estado, datos relevantes sobre el presidente Manuel Estrada Cabrera, así como de Miguel Ángel Asturias. Luego refiero algunos aspectos generales de la novela, para posteriormente ocuparme de temáticas desde una óptica más personal. El documento cuenta con la particularidad de mostrar un proceso de acompañamiento de la lectura que consistió en escribir versos correspondientes a capítulos de la novela, mayoritariamente décimas espinelas ${ }^{1}$, como meta inicial. Tal ejercicio aspira a documentar, mapear, reflexionar, describir o condensar aspectos relevantes de las temáticas, los personajes y los acontecimientos. La dificultad que representó realizar esta tarea derivó en el apoyo de estructuras más cortas llamadas redondillas ${ }^{2}$. Los versos abarcan dos de las tres partes de la novela, que resultaron en 25 décimas y 7 redondillas. Se incluyen como anexo.

1 La décima espinela cristalizó gracias a Vicente Espinel, músico y poeta del Siglo de Oro Español. Es una forma poética de estrofa de diez versos octosílabos, por lo general de rimas consonantes y perfectas que siguen el orden: ABBAACCDDC

2 Cuatro versos octosílabos que riman en forma ABBA.
\end{abstract}


Palabras claves: El Señor Presidente, novela, historia, décimas, Guatemala, Miguel Ángel Asturias, Centroamérica.

\begin{abstract}
This work gathers the context around the novel book El Señor Presidente (Mister President), published in 1946 by the Guatemalan writer Miguel Ángel Asturias. It briefly looks into History of Guatemala and its State, relevant details about president Manuel Estrada Cabrera, and the author's life. It addresses some general aspects of the novel book, to later refer to specific topics from my personal view. The paper has the particularity of showing a parallel accompaniment for the reading process. It consists of writing poetry verses according to the chapter structure of the novel, mostly décimas espi$n e l a s^{3}$ as an initial goal. Writing verses seeks to map out, reflect on, describe, or condense relevant aspects about topics, characters, and events. In some cases, difficulties forced me resort to a smaller verse structure called redondilla $^{4}$. Verses cover two of the three parts of the novel, and resulted in 25 décimas and 7 redondillas. They are attached to this work.

Keywords: Mister President, Novel, History, Décimas, Guatemala, Miguel Ángel Asturias, Central America

3 The décima espinela crystallized thanks to Vicente Espinel, musician and poet of the Spanish Golden Age. It is a ten-line stanza of poetry with octosyllabic verses that follow the consonant rhyming scheme: ABBAACCDDC

4 Four octosyllabic verses in a ABBA-rhyming scheme.
\end{abstract}

\section{Guatemala}

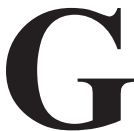
uatemala nace a la vida independiente el 15 de setiembre de 1821; se desenmarca así del Virreinato de Nueva España como la Capitanía General que fue en el período colonial. En los primeros años se destaca la segregación dada por la herencia colonial, expresada en la polaridad entre sectores criollos e indígenas como "dos repúblicas" (Taracena, 2002, p. 43). Así, jurídicamente coexistían por lo menos dos mundos reglados de manera distinta, con dominio para los grupos criollos como herederos del orden colonial. Para la población indígena (una generalidad que envuelve diversas etnias entre las maya-quiché) continuó el sistema colonial que les asignaba su estatus de fuerza laboral dentro del sistema socioeconómico. El dominio criollo va a verse socavado por el ascenso de un tercer grupo: el ladino. De origen mestizo, el grupo ladino se identifica con la cultura blanca y no con la indígena. Así, se atribuye el derecho a la explotación del indio como fuerza de trabajo para sus intereses, tal como los sectores criollos. 
Los grupos ladinos verán incrementado su peso como grupo social con la llegada al poder de Rafael Carrera en 1840, quien funda la República de Guatemala en oposición a esfuerzos previos que buscaban la integración en la Federación Centroamericana. Más tarde cristalizarán su dominio cuando se hacen del poder político en Guatemala con la revolución liberal en el año 1871. Con Justo Rufino Barrios al poder, los ladinos liberales empezarán la construcción del Estado y la Nación guatemalteca, con toda la dificultad que representa la división social y étnica que existe. En el plano económico, se trata de un Estado oligarca basado en el modelo agroexportador del monoproducto del café, que supervive hasta casi la mitad del siglo XX. Con los grupos liberales se profundizó la explotación de la mano de obra indígena, al tiempo que se les expropiaron tierras en función de la producción de riqueza que finalmente inscribiera al país dentro del sistema capitalista mundial. Esta inserción, basada en el servilismo y la explotación, con una marcada división racial del trabajo y consecuente separación de clases, está enmarcada dentro de lo que Sergio Tischler denomina "Estado Finquero" (Tischler, 1997). La garantía de este orden está dada por el ejército. Así lo comenta el historiador Rafael Cuevas:

Es precisamente como producto de las reformas liberales que se puede hablar del ejército moderno en Guatemala (fundación de la Escuela Politécnica en 1873); de ahí en adelante su presencia será determinante en la vida política del país lo que muestra la necesidad que han tenido las clases dominantes guatemaltecas de apoyarse en los aparatos de coerción antes que los de consenso (Cuevas, 1992, p. 26)

El uso de la fuerza a través del aparato militar para el ejercicio del poder desde el Estado es una característica histórica de varias experiencias en América Latina. En Guatemala esto deviene una tradición de Estado autoritario. Al respecto, Cuevas plantea que esta tradición:

Creció con vigor y rasgos propios, y sus constantes fueron, por un lado, la función ornamental de la ley, y por otro, el despliegue desordenado de la arbitrariedad personal lo que encarnó en la figura del dictador (civil o militar). La negación de la vida democrática se negó en dos dimensiones políticas: la incapacidad para asimilar la oposición y el abuso del monopolio legítimo de la violencia: la coacción física, la represión contra los opositores o los sospechosos (Cuevas, 1992, p. 26).

\section{Manuel Estrada Cabrera}

Manuel Estrada Cabrera (1857-1924), abogado espurio, dirigió de forma despiadada Guatemala durante 22 años: desde 1898 hasta 1920 . Se asentó en el poder por la fuerza después del asesinato del presidente José María Regina Barrios. Su gobierno se basó en el terror y la opresión. Un movimiento popular lo derrocó y fue encarcelado hasta el final de sus días.

Como ya lo mencioné, los liberales llevaron a cabo una transformación del país desde 1871 mediante varias reformas que buscaban la modernización, el orden y el progreso. De fondo Estrada Cabrera fue un continuador del proyecto liberal. Contaba con el beneplácito de los Estados 
Unidos. Durante su gobierno se estableció la United Fruit Company, hecho que compensó la balanza económica ante el estancamiento de la producción cafetalera por las diversas crisis de precio que el café experimentó. De esta forma, Estados Unidos jugaba un papel de gran importancia, pues estaba metido de lleno en la economía del país, al tiempo que financiaba el gobierno de Estrada Cabrera, lo que a él le permitiría mantenerse largo tiempo en el poder: 22 años, de hecho, el período más largo de un mandato en la historia del país.

Las políticas concesionarias fomentaron las economías de enclave y fuga de capitales, al tiempo que propiciaba la inmigración europea con la intención de "blanquear" y mejorar más la Nación. Como fue común en la región latinoamericana, esta política de entreguismo practicada por los liberales y que también continuó Estrada Cabrera, provocó que la red ferroviaria se viera extendida y fortalecida en favor de la producción y el comercio que las empresas extranjeras requerían. En su gobierno se terminó la línea hacia el Atlántico, lo cual propició mayor participación extranjera en Guatemala. También mejoraron las comunicaciones a través del telégrafo y el correo. Sus políticas tuvieron alcance en los niveles medios de la población, debido al auge económico que estos sectores empezaron a mostrar. Así, se ampliaron los servicios de salud y la educación por razón de la alfabetización.

A partir de su llegada al poder, Estrada Cabrera poco a poco fue ganando control político por un astuto manejo de las relaciones con el ejército, las divergencias partidarias internas del partido liberal y el conocimiento amplio del aparato estatal (Taracena, 1999). De acuerdo con Bernardo Arévalo (2015), sus políticas le garantizaron un contrapeso ante el ejército, al propiciar el fortalecimiento policial, dentro del cual se agenció la creación de una policía secreta que desató el espionaje como forma de control político cruzado. Estrada Cabrera dirigió un reacomodo de mandos en el ejército, basado en relaciones personales y lealtades. Con esto indujo a la fracturación más profunda de las divisiones internas de la milicia para su propio beneficio. En 1908 superó un atentado en su contra y ejecutó a sus autores para reorganizar una vez más el brazo armado. Esto terminó de afianzar su poder sobre el ejército. Su régimen se prorrogó a través de cuatro reelecciones. Con el estancamiento económico en el que había caído su gobierno, el descontento y revuelta de diversos grupos sociales, terminaría de poner contra la pared su mandato, que llega a su fin el 15 de abril de 1920.

En los últimos años, Estrada Cabrera ya no pudo dar una orientación adecuada a las cambiantes necesidades de la nación. Para cuando su propio partido se volvió contra él para quitarle el poder en 1920, su gobierno había degenerado en una dictadura aislada y paranoica incapaz de continuar proveyendo el progreso material que había definido como su raison d'etre. (LittleSiebold, 1994, p. 38)

Estrada Cabrera encarna el dictador civil de El Señor Presidente, de Asturias, ese que no necesita ser militar para ejercer el poder con violencia. 


\section{El autor}

Miguel Ángel Asturias nació en Ciudad de Guatemala en 1899, un año después de la llegada al poder de Manuel Estrada Cabrera, el "señor presidente" de su novela. Valga decir que, durante sus primeros veinte años de vida, Asturias solo conocería a una persona en el poder.

Muy joven, en su época estudiantil universitaria, se convierte en un férreo crítico y opositor del gobierno dictatorial de Estrada Cabrera. Junto a otros estudiantes, conformó el grupo de la llamada "Generación del 20". De acuerdo con Taracena (1999), este grupo estudiantil integró, a su vez, el "Club Unionista de Estudiantes Universitarios, el cual aglutinó a alumnado de medicina, farmacia y derecho a inicios de 1920. El club fue un brazo importante del opositor Partido Unionista, que "con base en la estrategia planeada por su líder Manuel Cobos Batres, vio la importancia de impulsar la organi- zación de los estudiantes como una de las fuerzas sociales que garantizarían la caída de la dictadura" (p. 90). Asturias se graduaría como abogado en 1923 y un año después partiría hacia Europa, desde donde, a distancia, siguió muy activo como comentarista de los acontecimientos de Guatemala, la cual se encontraba nuevamente en manos entreguistas de gobiernos militares - liberales. Durante su estancia en Europa escribió El Señor Presidente, entre los años 1925 y 1932.

A su regreso a Guatemala en el año 1933, Asturias se incorporó a la vida política desde varios periódicos, desde donde enunció su postura de denuncia de las desigualdades, de defensa de la soberanía y de preocupación por transformar a Guatemala en algo mejor. Le caracterizó un nacionalismo latinoamericanista antiimperialista con perspectiva centroamericana, influenciado por el peruano Víctor Raúl Haya de la Torre. De acuerdo con Taracena, aunque un joven Asturias tenía una visión bastante completa de la diversidad étnica guatemalteca por la falta de homogeneidad de la Nación, el influjo positivista y evolucionista de la época lo hacía partidario del mejoramiento de la raza a través del "blanqueamiento" como forma de resolver el "problema indígena". También sugería la educación y el cambio de costumbres para que este populoso sector de la población se incorporara con mejor suceso a la nación guatemalteca y se combatiera la degeneración de los individuos (Taracena, 2002, p. 112). La activa participación política llevaría a Asturias a ser diputado y a extender una carrera diplomática. Entre otros premios, destaca el Nobel de Literatura otorgado en 1967 por su obra completa. Asturias es el único centroamericano en haber obtenido ese reconocimiento. Murió en París en 1974.

\section{La novela}

El Señor Presidente de Asturias publicó hasta 1946, 13 años después de haber sido terminada, debido a que el contexto de los gobiernos guatemaltecos no garantizaba una publicación libre de censura. La novela se basa en el mandato de Estrada Cabrera, como ya se mencionó. Constituye uno de los hitos de la literatura latinoamericana y ha sido ampliamente reconocida y estudiada. Su temática la coloca dentro de lo que el crítico literario chileno Ricardo Gutiérrez explica como 
el complejo de "novela del dictador". En el artículo La letra y el letrado en El señor presidente, Gutiérrez se refiere a un aspecto, a su juicio, poco abordado. Se trata del origen oral de la novela en asociación con el mito cultural latinoamericano del dictador. Resalta que Asturias mismo así lo había aclarado: "[El libro] No fue escrito, al principio, sino hablado. Fue deletreado. Era la época del renacer de la palabra, como medio de expresión y de acción mágica. Ciertas palabras. Ciertos sonidos. Hasta producir el encantamiento, el estado hipnótico, el trance" (Gutiérrez, 1987, p. 643). La producción del texto a partir de lo oral puede analizarse como el apresamiento que lo escrito hace de lo dicho. En este sentido, en la novela hay una correspondencia entre los varios momentos en que se sitúa la prisión como lugar donde las declaraciones y testimonios (orales) son totalmente tergiversados y escritos de otra manera, lo que retrata un sistema legal completamente viciado, arbitrario y disfuncional. (Gutiérrez, 1987). Un ejemplo de esto es cuando Lucio Vásquez es interrogado acerca de las razones por las que asesinó al Pelele (orden presidencial) y el Auditor hace que el amanuense escriba lo que sea funcional para la condena de Vázquez. Así reacciona el Auditor:

¡Ni una palabra, ni una palabra más! ¡Mañas conmigo! ¡Presidentazos conmigo! ¡Bandolero, yo no soy niño de escuela para creerle tonterías de ese jaez! El dicho de una persona no hace prueba, salvo por los casos específicos en los Códigos, cuando el dicho de la policía funge como plena prueba... (Asturias, 1985, pp. 197-198)
No es de mi interés ahondar en el análisis de Gutiérrez, el cual encuentro muy revelador e interesante en términos de cómo la novela al escribirse "traiciona" su preexistencia oral y le arrebata su libertad. Más bien quiero mencionar el hallazgo que esto representa ante mi propuesta de escribir décimas como manera de mapear y estructurar la novela en otro canon; en otra forma, es decir, en un material intencionado, cuya estética deviene contenido en sí mismo. La relación consiste en que la forma de verso que es la décima proviene de una tradición que en Latinoamérica se desarrolló en el ámbito de la oralitura y la improvisación poética. Se trata de la organización de un microuniverso con reglas particulares que se sostienen rítmicamente mediante la pronunciación de la palabra. Esto representa para mí una simpática correspondencia con el proceso de confección de las décimas, como si de alguna manera aportaran a la 'libertad' de la palabra apresada por lo escrito. También porque mi afán por crear las décimas precedió al descubrimiento de los planteamientos de Gutiérrez y el mismo Asturias respecto de la oralidad.

La décima que cristalizó como forma se le atribuye al español Vicente Espinel en el año 1591. No en vano se le conoce como "espinela" a esta estructura de diez versos octosílabos que riman de forma ABBAA-CCDDC. Fue ampliamente propagada por América Latina, donde adquirió nombres específicos según el lugar en que se practicara. 


\section{Apuntes sobre contenidos}

De la diversidad de temas que son relatados en El Señor Presidente, selecciono dos para los cuales desarrollo ideas a partir de análisis propio en relación con el contenido sociohistórico presente en la obra. Para esto, utilizo como ejemplos de reflexión, reescritura o ilustración algunas de las décimas que escribí como suerte de navegación acompañante de la lectura de la novela.

\section{EI dictador y el Estado autoritario}

En la novela se relata la historia de varios personajes que gravitan alrededor del Señor Presidente tal y como lo representa Miguel Cara de Ángel, uno de los generales de confianza que, por el mismo presidente, acabará siendo declarado enemigo, emboscado y encerrado en condiciones infrahumanas hasta su muerte. La historia de este general -"bello y malo, como satán"revela el juego de lealtades y traiciones en las que se desenvuelven los altos mandos del ejército. El círculo de personajes militares están claramente cooptados por el presidente al nivel de la humillación. Todos le temen y le respetan, con lo que queda totalmente clara la magnitud del poder que el presidente tiene. Una forma con la que Asturias refuerza esto se manifiesta en la no presencia del presidente en las acciones que se relatan, a manera de un ente invisible y panóptico que gobierna sin ser visto. Las apariciones del presidente son muy puntuales. Y en eso se sustenta también un régimen dictatorial: una experiencia (dicho sea de paso, recurrente en América Latina) donde la coerción impera a través del miedo, que se logra instaurar en la colectividad. La arbitrariedad del ejercicio del poder también se ve repartida en todo aquel alto o medio mando que como autoridad tiene para hacer y deshacer, con lo que la ley resulta un instrumento completamente "ornamental" (Cuevas, 1992, p. 26).

En la novela la figura del dictador también se aborda como concentrador de las decisiones que competen al país. Así se muestra en el capítulo XXXVII:

- Aquí, Miguel, donde yo tengo que hacerlo todo, estar en todo, porque me ha tocado gobernar en un pueblo de gente de voy -dijo al sentarse-, debo echar mano de los amigos para aquellas cosas que no puedo hacer yo mismo. Esto de gente de voy -se dio una pausa-, quiere decir gente que tiene la mejor intención del mundo para hacer y deshacer, pero que por falta de voluntad no hace ni deshace nada... (Asturias, 1985, pp. 370-371).

Esa centralización del poder se puede atar a aquella enunciación de "El Estado soy yo" de Luis XIV, donde las diferencias entre un dictador y un monarca se desdibujan. La figura del dictador también se sacraliza. El mundo que gravita a su alrededor se encargará de dotarlo de una constitución divina en un juego de adulación, idolatría y patriotismo. Esto involucra la mezcla de imaginarios religiosos y nacionalistas. La décima que escribí sobre el capítulo XIV intenta recoger esta particularidad, cuando durante las fiestas nacionales el presidente sale al balcón presidencial a dar un discurso, donde más bien es vitoreado por la muchedumbre que le respalda: 


\author{
XIV Todo el orbe cante \\ Patria, Discurso, Balcón, \\ Padre, Señor, Presidente, \\ Hijo del Pueblo, Elocuente \\ Ciudadano de la Nación \\ República, Pabellón \\ ¡Salve Ave Fénix-Quetzal! \\ Gran Partido Liberal \\ Demócrata Protector \\ ¡Gloria!, Aplauso, ¡SEÑOR! \\ ¡Viva! ¡Fiesta Nacional!
}

Esta décima está construida a partir de palabras clave del capítulo, que evocan casi un himno-salmo. Las mayúsculas están usadas intencionalmente en favor de ese carácter exaltado del patriotismo nacionalista y la adoración que se le expresa al señor presidente.

El mundo constituido a través del autoritarismo otorga al presidente y a otros personajes posiciones de ventaja ante las demás personas. La lealtad es un valor importante que entra a jugar dentro de estas relaciones de poder. Dicha ventaja puede significar beneficios para otros grupos, en el sentido de acceder a favores, permisos, indultos, trabajo, dinero, etc. Esto se expresa en el fenómeno del padrinazgo, el cual está presente en el sistema de relaciones sociales y de gobierno que se configuraron en los países de América Latina. En su sentido estricto, lograr que una persona de cierta posición social se convierta en compadre o madrina de un infante se vuelve una forma de garantizar algunos beneficios para quienes se ven en condiciones de mayor necesidad. Así sucede con Niña Fedina, esposa de Genaro Rodas, quien busca que Camila, hija del General Eusebio Canales, se convierta en madrina de su bebé con el fin de asegurarle una posible vida mejor. Este tipo de relaciones también se expresa fuera de la esfera familiar en el ámbito público: el compadrazgo entre mandos del ejército y gobierno. La lealtad garantiza seguridad, confianza o enriquecimiento incluso. Quien traicione este valor será objeto de persecución, emboscada, prisión, tortura o asesinato. La violencia sicológica y física de la tortura aparece con frecuencia en el relato. Esta décima intenta condensarla:

\section{Coyotes de la misma loma}

¿Quién pregunta? ¿Quién contesta?

(Según el lado en que esté)

(No vale de nada la fe)

(Si es honesta la respuesta)

(Pues el que pregunta detesta

que se diga la verdad)

(Y tortura con maldad

a quien inocente niega

versión oficial) (Se le pega

palo a palo, ¡sin piedad!)

\section{Tema no-tema. La mujer}

La razón de señalar este tema obedece, quizás, a la naturalización de la subordinación histórica de la mujer hacia el hombre. De esta manera el tema se vuelve tácito, pues se asume la condición de la mujer como sabida. En este sentido quiero referirme a él como no-tema para visibilizar lo visible, es decir, lo que ante nuestros ojos es tan obvio que lo invisibilizamos. Yo mismo pasé por ese proceso mientras leía la novela y no fue sino hasta cierto momento cuando reflexioné sobre la forma en que estaba leyendo y que determinaría los temas de análisis que ambicionaba tratar en este trabajo. La condición de la mujer en la novela está dada por un sistema patriarcal magnificado por el estatus dictatorial de su contexto. Una dictadura militar se puede leer, a mi juicio, como 
una extensión o aumentación del poder y la violencia que ejerce el hombre sobre la mujer. Así, completamente procedente se vuelve la violenta y antojadiza idea que tiene el General Cara de Ángel de raptar (!) a Camila, hija de Eusebio Canales, con el fin de desposarla (Asturias, 1985, pp. 97107). Las siguientes décimas corresponden a los capítulos XI y XII que tratan sobre la situación arbitraria y de violencia machistapatriarcal a la que se ve sometida Camila:

\author{
XI EI rapto \\ Velada nada halagüeña \\ la que Canales afronta. \\ Una treta de poca monta \\ Cara de Ángel diseña \\ para raptar la trigueña, \\ hija de ese perseguido. \\ Huye Eusebio, urgido, \\ con una ingenua esperanza: \\ Volver y ejercer venganza. \\ Poder que se ha corrompido.
}

\section{Camila}

El plan se ha concretado. Aquel emprendió la huida. De raptada a protegida la pobre Camila ha pasado A manos del que ha trazado la jugada: El favorito. Cara de Ángel, ¡maldito! -Tu padre a salvo va a estar-, le miente cruel sin dudar con un cinismo inaudito.

Esta situación que atraviesa Camila (de 15 años) cobra un giro inusitado que transforma la condición de víctima de Camila, al pasar de raptada a protegida y de protegida a esposa luego de superar una pulmonía. Sin alguna concatenación lógica más allá de la naturalización de esa subordinación, en Camila aparece el amor por su raptor.
Ese sentimiento la llevará a la espera de su ahora marido, quien ha sido emboscado y traicionado por el Señor Presidente. Su espera se enmarca en la clásica imagen de fidelidad, negación de la pérdida, esperanza por el retorno y sufrimiento por el hombre.

De donde se puede leer este no-tema con mayor intensidad, el capítulo XVI es de los más desgarradores. El Auditor apresa a Niña Fedina y le tortura al mismo tiempo que a su bebé, al impedirle amamantarse. El niño muere en brazos de su madre (Asturias, 1985, pp. 153-168). Posteriormente, el capítulo XXII narra cómo el Auditor vende a Fedina, completamente violentada, a un prostíbulo (Asturias, 1985, pp. 209-218). La siguiente décima surgió de la imposibilidad de narrar hechos tan dolorosos y a partir de la reflexión que hice sobre el no-tema:
XXII La tumba viva
Es la historia un hombre
y vos reverso, mujer.
Clama tu cuerpo no ser
aquella figura sin nombre.
Te comercian sin que asombre,
en vida te arrancan la vida.
Madre-hija-hermana herida.
Un hombre también es un arma,
una militar alarma
homo-infanti-femicida.

La siguiente décima refiere a la explotación sexual de las mujeres, la cual toma lugar en el prostíbulo de doña Chon, como se relata en el capítulo XXIV. Todas son diferenciadas y descritas a partir de su aspecto y sus apodos, mientras que los hombres se describen por su profesión o nivel socioeconómico, como sexo-género que tiene el privilegio de la esfera pública y el anonimato e impunidad detrás de la explotación. 


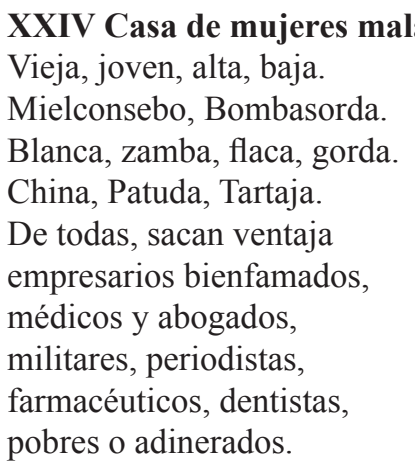

Los ejemplos de Fedina, Camila y las prostitutas denotan la violencia patriarcal y el carácter de propiedad de la mujer que se atribuye el hombre. Como lo he mencionado, esto se encuentra naturalizado. Se trata de una problemática vigente y común en las sociedades de América Latina que se ha venido complejizando a través de la historia y que se replica globalmente en el sistema-mundo patriarcal y capitalista.

\section{Conclusión}

El Señor Presidente, de Miguel Ángel Asturias, representa una pieza literaria hito de América Latina. A través de ella se puede leer el contexto conflictivo caracterizado por un Estado autoritario y militar condensado en la figura del dictador. Manuel Estrada Cabrera, a quien alude la novela, representa esa figura de poder omnipresente que continúa con el proyecto liberal y oligarca en Guatemala a partir de la violencia de Estado, de relaciones espurias, de compadrazgo y de políticas entreguistas, entre otras características. La novela contribuye también a una reconstrucción de la memoria colectiva que va más allá del escenario guatemalteco y trasciende hasta América Latina.
Dentro de los hallazgos relativos a la construcción de la novela y la temática que desarrolla, se encuentra la oralidad como génesis del texto. Este relato oralizado se ve "apresado" en el momento en que se pasa al medio escrito, metáfora misma de las arbitrariedades de un poder dictatorial que encierra, tortura y mata a través la fabricación, tergiversación o inexistencia de pruebas y testimonios donde lo dicho constituye una libertad coartada. En este sentido, el poder dictatorial y el uso de la fuerza da cuenta de la violencia que se traslada a los ámbitos de relaciones sociales y políticas, mediante las distintas jerarquías que emanan del presidente como centro. Se extiende también a un contexto magnificado de violencia hacia las mujeres en todos los niveles: físico, sicológico, estructural y simbólico. Esto constituye uno de los aspectos más desgarradores de la novela.

Como particularidad de este trabajo, el acompañamiento de la lectura realizado a través de las décimas representa una forma alternativa en la que pude hacer síntesis de contenidos y aspectos de interés de la novela. La novela funcionó como un complejo "pie forzado" 5 para la ejecución de las décimas. Resalto su vínculo con la génesis oral de la novela, al ser la décima una forma poética perteneciente al mismo ámbito de la oralidad. A través de esta suerte de re-lecto-escritura, la persona lectora puede recorrer alternativamente la novela.

5 Los pies forzados son temas, frases o palabras que determinan la décima como pauta de contenido. 


\section{Anexo 1}

\section{Décimas}

Estos versos, mayoritariamente décimas espinelas, representan un proceso experimental de acompañamiento a la lectura del libro en dos de sus tres partes. Es de alguna manera, caótico en su estilo y forma de incluir detalles significativos. En ese sentido, no explican el relato, pero lo mapea, relee y reescribe en algunas de sus dimensiones. Algunas veces las décimas han tenido que verse reforzadas o sustituidas redondillas. Otras veces se han flexibilizado en sus reglas.

\section{En el Portal del Señor}

Luz de lumbre piedralumbre de la Plaza al Portal del Señor donde gente de clase menor para a dormir por costumbre. En su sobrepodredumbre: Un ciego (el Mosco), el Viuda, un borracho, una sordomuda, El Pelele, el Patahueca. Gente con la vida chueca Ni la sombra les saluda $---$

Solloza y grita el Pelele Que digan 'madre' no soporta La pena le llega a la ahorta Cuerpo y alma: todo duele. $\mathrm{Y}$ cuando todos le repelen de la sombra viene a él un milico de Luzbel que lanza un -Madre- con su boca. Locura al Pelele provoca y loco mata un coronel

\section{En el calabozo de Las tres Marías}

"Crimen político" juran los policías que apresan a los mendigos que expresan:

-"Fue el idiota"-, lo aseguran.
Sin contemplar les torturan para inculpar dos señores, más convenientes autores que el Mosco se niega aceptar Y así, le mandan callar. Con muerte se apagan rumores.

\section{La fuga del Pelele}

Elude el alba, la ciudad -Huye ya, Pelele, ¡Huye!Del trastorno se escabuye de basura, de enfermedad, el delirio, la tempestad, fiebre dura, la pierna rota... De un picotazo su boca explota. De zopilotes es alimento. ¡Erre! ¡Madre! Su tormento. ¡Erre! ¡Fuga! ¡INRI, Idiota!

\section{IV ;Cara de Ángel!}

Cae, sueño, moribundo El Pelele pide perdón A la madre-alucinación que le da paz un segundo Más allá que acá en el mundo, Un leñador lo recoge (Divino ángel le escoge) para aliviar al herido) Lo carga todo el recorrido y en su rancho le acoge

\section{$V_{\text {¡Ese animal! }}$}

Don Luis Barrero es doctor del hospital militar.

A él lo manda llamar

El Presidente Señor

-Luis, que no hable, es mejor-, amenaza al doctor en la sala, (Porque es cosa muy mala la que le puede ocurrir. Como Ese animal, morir A palos, manos o bala)

-¿Quién mató al coronel Sonriente?preguntan los militares. -¿Crimen producto de azares?-, duda el Señor Presidente. 
VI La cabeza de un general

Ya lo ordenó el presidente

y Cara de Ángel será

quien a Canales dirá

que huya el día siguiente

declarado delincuente:

Asesino de José Parrales

(Estrategias presidenciales

para anular enemigos)

Sin dejar mayores testigos

rodarían cabezas rivales

\section{Absolución Arzobispal}

Rápido se ha rumorado entre voces policiales que Carvajal y Canales a Parrales han matado ¿No habrá aquí gato encerrado? Vázquez y Rodas sospechan (El primero, tomado, pertrecha) terminar el sufrir del Pelele.

Que su vida se cancele, con dos balazos le flecha)

\section{El titiritero del portal}

De la plaza a los callejones

cercanos se han oído

nada alegres alaridos

Después de dos detonaciones

Un matrimonio de mirones

(El titiritero y su esposa)

Intentan descifrar qué cosa

pasó que un cadáver retiran.

Desde su puerta lo miran:

Escena nada "graciosa"

\section{Ojo de vidrio}

Genaro regresa muy tarde

A casa, a su hijo y mujer.

Perturbado no para de ver

un fantasma, la culpa le arde

Fruto del hecho cobarde

Que Vázquez libró sin sonrojo

haber presenciado el despojo

A la vida de aquel desdichado

El Pelele, muerto, lo ha mirado:

a Rodas persiguen los ojos.

\section{Príncipes de la Milicia}

Su disyuntiva, Canales:

Escapar lo vuelve culpable.

No hacerlo vuelve palpables

las consecuencias fatales.

Por causa de frases triviales...

(disgustaron al Presidente)

$\mathrm{Y}$ aunque Eusebio es inocente, no tiene el favor del amo, quien le ha inventado el reclamo de asesinar a Sonriente

\section{EI rapto}

Velada nada halagüeña la que Canales afronta. Una treta de poca monta

Cara de Ángel diseña para raptar la trigueña, hija de ese perseguido. Huye Eusebio, urgido, con una ingenua esperanza:

Volver y ejercer venganza.

Poder que se ha corrompido.

\section{Camila}

El plan se ha concretado. Aquel emprendió la huida. De raptada a protegida la pobre Camila ha pasado, a manos del que ha trazado la jugada: El favorito. Cara de Ángel, ¡maldito! -Tu padre a salvo va a estar-, le miente cruel sin dudar con un cinismo inaudito

\section{Capturas}

Preocupada de lo que pasa corre a escena la Fedina ¿El proyecto de madrina para su hijo fracasa?

Llega y se mete a la casa donde el desastre ha ocurrido Medio lugar destruido, la sirvienta casi muerta ¡Capturada Fedina en la puerta!, hurgaba donde es prohibido 
XIV Todo el orbe cante

Patria, Discurso, Balcón,

Padre, Señor, Presidente,

Hijo del Pueblo, Elocuente

Ciudadano de la Nación

República, Pabellón

¡Salve Ave Fénix-Quetzal!

Gran Partido Liberal

Demócrata Protector

¡Gloria!, Aplauso, ¡SEÑOR!

¡Viva! ¡Fiesta Nacional!

\section{Tíos y tías}

Según aquel plan por cuajar

Camila se irá con su tío

El señor Juan Canales, que frío

ve al favorito llegar

a su casa para concertar

lo que el prófugo Eusebio quería.

Pero claro revés se daría.

Los tíos dan mal veredicto:

¿Aquí la hija de un convicto?

¡Mal visto por todos sería!

\section{En la casa nueva}

¿Dónde está el general?

¡Contesta! ¡Fedina, mujer!

Tortura hasta el amanecer.

Tortura moler viva cal.

Tortura destino fatal.

¡Dolor! Y queda sin comer, sin pecho de dónde beber, tu niño que solo llorar.

Inhumano placer militar.

Despreciable perverso poder.

\section{Amor urdemales}

¡Angustia! Noticias espero

¿Qué es de mi padre en fuga?

¡El corazón se me arruga!

¡Dígame su paradero!

Cara de Ángel confiesa porque La Fondera ha hablado...

Culpable y avergonzado,

él sus motivos expresa
¡No creás nada; sos presa

Camila, de este engreído!

Miguel... que ha definido

tenerte por posesión

sin importar la razón

ni si vos lo has querido

$--$

Lucio Vásquez arrestado

Genaro Vásquez lo cantó

La Fondera no entendió

Que el plan se ha revelado

\section{Tosquidos}

Camila ha pedido buscar

Donde su tío acogida

$\mathrm{Y}$ en su urgente venida

su tío le va a rechazar,

A puerta cerrada negar

cualquier refugio posible

Y lo que parece increíble

ahora se vuelve verdad:

Mezcla de miedo y crueldad

en su familia, legible.

\section{Las cuentas y el chocolate}

$---$

\section{Coyotes de la misma loma}

¿Quién pregunta? ¿Quién contesta?

(Según el lado en que esté)

(No vale de nada la fe)

(Si es honesta la respuesta)

(Pues el que pregunta detesta

que se diga la verdad)

(Y tortura con maldad

a quien inocente niega

versión oficial) (Se le pega

palo a palo, ¡ $i$ in piedad!)

\section{Vuelta en redondo}

La culpa lo impide a él.

No puede dormir ni llorar

Tierno-cruel militar

Bello y malo cual Luzbel

Cara de Ángel, Miguel

Consciente de la cobardía 
Que a Camila él le haría

Ella desesperanzada de dolor cae acostada víctima de pulmonía

\section{La tumba viva}

Es la historia un hombre y vos reverso, mujer. Clama tu cuerpo no ser aquella figura sin nombre. Te comercian sin que asombre, en vida te arrancan la vida.

Madre-hija-hermana herida.

Un hombre también es un arma, una militar alarma homo-infanti-femicida

\section{El parte al Señor Presidente}

1. Solicitudes de audiencia

2. Peticiones de absolución

3. Rumores de revolución

llegan a la presidencia.

(Ávida correspondencia

que pone al tanto al Señor)

Él así sabe mejor

cómo cercar enemigos

y quiénes fieles amigos

son del civil dictador

\section{Casa de mujeres malas}

Vieja, joven, alta, baja.

Mielconsebo, Bombasorda.

Blanca, zamba, flaca, gorda

China, Patuda, Tartaja.

De todas, sacan ventaja

empresarios bienfamados,

médicos y abogados,

militares, periodistas,

farmacéuticos, dentistas,

pobres o adinerados.

\section{El paradero de la muerte}

La dolencia se vuelve más fuerte

Un cura confiesa a Camila

Su ángel custodio vigila

Al pie de la cama: la muerte
El Cara de Ángel, truhan se ha inventado otra trama que por Camila a quien "ama"

Despista al mayor Farfán

\section{Torbellino}

Frío, calor, y delirio.

Camila, funesta, salud, preclara visión, ataúd, pende de un hilo, equilibrio, cama, postrada, martirio.

Sueño, culpa, favorito,

Mal de consciencia, bendito,

¡Bravo! visión, pesadilla, pantalón rojo, una silla

Auditor come, maldito.

\section{Camino al destierro}

Canales en fuga, calvario.

El camino le da lecciones:

Injusticias y abyecciones

el pueblo las sufre a diario.

Estado-poder victimario, de su tierra al indio despoja.

A las muertas también desaloja.

Militar hace conciencia, cómplice de la falencia.

Revolución: paradoja

\section{Indio despojado}

Alcalde y comisionad $e^{6}$ mis besties se han repartide, de mis hijos me han desprendide, y han mi tierra robade

\section{Ayuda \\ Aquellas amigas solteras \\ Al perseguido ayudaron \\ Luego de que lo ocultaron \\ Pudo cruzar las fronteras}

6 A la manera en que Asturias escribe el 'mal castellano' que habla del indio. 


\section{Referencias}

Arévalo, B. (2015). Del Estado violento al ejército político: Violencia, formación estatal y ejército en Guatemala, 1500-1963 (Tesis doctoral). Países Bajos: Utrecht.

Asturias, M. (1985). El Señor Presidente. San José, Costa Rica: EDUCA.

Cuevas, R. (1992). Estado y cultura en Guatemala y Costa Rica. Anuario de Estudios Centroamericanos, 18(2), 25-39.

Gutiérrez, R. (julio/setiembre, 1987). La letra y el letrado en El Señor Presidente, de Asturias. Revista Iberoamericana, 53(140), 643-650.
Little-Seabold, T. (1994). Guatemala y el anhelo de modernización: Estrada Cabrera y el desarrollo del Estado, 1898-1920 Anuario de Estudios Centroamericanos, 20(1), 25-41.

Taracena, A. (diciembre, 1999). El camino político de Miguel Ángel Asturias. Mesoamérica, 38, 87-101. Guatemala: CIRMA.

Taracena, A. (2002). Etnicidad, Estado y Nación en Guatemala, 1808-1944. Etnicidad, Estado y Nación en Guatemala. Guatemala: CIRMA.

Tischler, S. (agosto, 1997). La forma finquera del Estado, una aproximación al Estado liberal oligárquico guatemalteco. Revista Estudios, 2, 108-135. 
